\title{
Privacy, risk and good and bad consumers
}

\author{
Bryan Foss \\ has recently started to work as an independent customer management and customer experience adviser and implementer in \\ both consumer and B2B markets worldwide. As a partner in Foss \& Stone Marketing (FSM), Bryan is also an associate of \\ Insight Marketing \& People (www.insight-mp.com) and Customer Essential (www.customeressential.com). Until mid-2005, \\ Bryan was leading an IBM business providing and integrating customer insight and front office customer management \\ solutions for retail banks and other financial services companies globally. Prior to that, he was responsible for IBM's business \\ relationship with the Prudential Corporation, worldwide, over a 6 year period. Previous experience included a similar period \\ working as IBM's technical management contact with American Express Card and Travel services, supporting all non-US \\ business operations. He was author and coauthored a number of books and reports, is a frequent presenter at financial \\ services and CRM conferences around the world and is the IT Editor of the Journal of Financial Services Marketing and an \\ editorial board member of the Journal of Database Marketing \& Customer Strategy Management and the Journal of Interactive \\ Marketing.
}

\begin{abstract}
Alison Bond
is a director of ABA Research Ltd (abaresearch@aol.com), a firm specialising in services research in consumer, business and public sector markets. Alison's researches into customer services and customer experience has helped many organisations completely rethink their views on the role and execution of their service and on their delivery business strategies. She managed one of the country's leading data processing research companies before starting ABA Research in 1995. Alison is a vastly experienced focus group facilitator and has moderated hundreds of groups during her career. She is the author of the highly acclaimed Direct Hit, a textbook on direct marketing. She writes numerous articles on customer service and measurement and is a full member of the Market Research Society (MRS). Her latest book The Handbook of Direct and Interactive Marketing was published by Pearson in 2005.
\end{abstract}

\section{INTRODUCTION}

Technology and data sources now make it possible for companies of all sizes (not just large) and government organisations to differentiate between 'good' and 'bad' individuals and groups. These developments also make it much easier to predict likely 'goodness' or 'badness' using various indicators. Where use of these indicators is forbidden for some reason, surrogates may be sought. Following this approach requires an organisation to define what it means by 'good' or 'bad', and to keep this definition under review according to the performance of individuals and evolving law and regulation.

Bryan Foss, $\mathrm{Tel} / \mathrm{Fax}$ :

+44 (0) 2087761363

e-mail:

bryan_foss@yahoo.co.uk

\section{WHO ARE GOOD CONSUMERS?}

Of course, 'good' and 'bad' are relative terms. Their definitions change with time, with laws and with the strategies and target marketing of companies. One also needs to distinguish between character and behaviour. A consumer who might naturally be 'bad' for a company may be constrained to be 'good' by product design or service management. Social and economic factors (the economy, neighbourhood) combine with an individual's characteristics to determine goodness and badness. In the private sector, good individuals are broadly defined as a mixture of some or all of the characteristics listed below. Companies can specialise in dealing with consumers who are 'not good' for other companies however, turning them into 'good' customers. Thus, some store credit cards are targeted at consumers who are less creditworthy, possibly because of imprudence, or simply low income. So this should be taken more as an example of the spectrum. 
1 Good net value. They yield more value to the supplier than it costs to service them, taking into account all costs. Consider the consumer who keeps a reasonable bank current account balance, never goes into debt without permission and rarely goes to the branch, but uses cash machines. This consumer is of higher net value than one with the same average balance who constantly moves into a small but free overdraft and uses branch services. Even though the latter might pay higher bank charges, these may not compensate for the extra costs of staff constantly checking to see whether the overdraft will be paid off. Though the bank might try to raise charges to the latter to make the account profitable, it may not succeed.

2 Moral (ie not fraudulent). They stay on the right side of the law in dealings with the company. Some companies do well by meeting the needs of consumers who would be considered immoral by most, but stick to the law while interacting with the company eg casinos or betting shops used to launder money.

3 Prudent. They live their lives within the resources available to them. Note that some companies make a very good living out of the imprudent, even if it does necessitate charging usurious interest rates!

4 Punctual - pay bills on time, arrive for flights in time, are at home for service appointments.

5 Responsive in a relevant way to communication. They respond to marketing communications that are relevant to them (in the sense that they are likely to lead these consumers to evaluate seriously the possibility of buying the product or service). However, they do not respond to ones that are not.
6 Responsive to other initiatives; eg willing to try new products.

7 Happy to give relevant and truthful information to the organisation and to update information previously given. This allows the organisation to determine the appropriate 'treatment' for the individual, but also to save resources by not offering inappropriate treatment. This also applies to complaints (see below).

8 Healthy in habits; eg moderate drinking, not smoking and perhaps even in genes.

9 Safe; eg in driving and as a pedestrian and perhaps in sporting habits.

10 Observing rights and responsibilities; eg prepared to learn to work with the organisation for mutual benefit, such as installing security devices, looking after credit cards, following a healthy life style.

11 Complaining only when 'justified', allowing the organisation to improve its service and reduce later complaints.

12 Prepared to recommend to other individuals if the service or product is good etc.

13 Persistent; ie not switching - though this depends on the product. Persistent consumers for undertakers are rare (though if the family is the decision-making unit, persistence can exist). Persistent consumers for wedding wear might also be persistent consumers for lawyers, because they can afford to be and hence possibly good consumers for financial services advisors!

14 Stable or predictable. Consumers can be good in one domain and bad in another. It is the stability of this pattern and, perhaps, more importantly the stability of individuals as members of groups which allows organisations to trade with them profitably. Although in theory all risks 
can be managed via insurance, when it comes to the balance of risk and value, stability may be the key. For example, a high street retailer setting up a new store may reckon on a particular level of abuse (credit default, shop theft, staff fraud) based on experience with similar stores, as well as a particular level of trade. If each new store displays the same pattern, the loss level is acceptable and standard control procedures can be deployed. If a new store displays different patterns, new approaches to management may be needed.

Again, it must be stressed that these are examples of characteristics that indicate 'goodness' for many companies, but may also be counter-indications for other companies. In some cases, the combination of attributes is important, rather than the possession of individual attributes.

\section{WHO ARE BAD CONSUMERS?}

Bad consumers have characteristics largely the opposite of those listed above. For most organisations, a key bad characteristic is current and/or likely future unprofitability, though sometimes unprofitable consumers may be valued eg as recommenders. Companies may include in their definition of bad consumers debtors, switchers, liars, or those with court judgements against them. Charities, public sector bodies or private sector bodies acting on behalf of these organisations, however, often focus on such consumers. Examples of bad consumer behaviour are numerous. Some are politically incorrect! Despite this, it is important that management (and government) understands the origins of 'bad' consumer behaviour, as solutions cannot always be found at an individual level. For example, many immigrant communities in Western nations are effectively economic or political refugees. They come from developing or poorer countries where to survive they had to 'look after their own', hiding as much from the government as they could because they were targeted for 'special attention' by the state. It may take generations before members of these ethnic or national groups adapt their behaviour to the more equitable treatment they should in theory receive from the government of their adoptive state, so, they may be reluctant to give personal information, for fear of it being exploited by state or company to their disadvantage. They may conceal income from tax authorities.

As companies seek to manage consumers more as individuals, but remotely, so some bad consumers learn to exploit this tendency. This is most visible in the areas of credit and debit cards and the internet, but also in insurance and banking. Bad consumers learn very quickly - because the incentive (the potential gain) is large - and in some cases transfer their learning very quickly (often to other individuals within an organised criminal network, but sometimes also within their ethnic or professional group or geographical locality). For example, government benefit frauds are often organised within ethnic groups or families. Tampering with utility meters often spreads geographically. In one London borough a utility company couldn't understand why so many of its meters had rusted. After replacing over a hundred it decided to do some undercover investigation. The company discovered that the someone had made a mould of the coin required for the meter and sold it to many local residents, this mould was then filled with water and frozen. The pieces of ice were then used to feed the 
meters. This method no longer works as meters have been adapted to prevent it.

Some consumers target particular types of organisation. Government and utilities are often regarded as 'fair game', by individuals across the economic spectrum. In the UK, privatised companies (eg utilities, rail companies), whose directors were labelled as 'fat cats' by the government when they profited from big increases in salary or from selling shares at great profit, became a 'legitimate target'.

Certain industries always have relatively high risk/value ratios at the level of the individual consumer. These are mostly those with a large insurance, credit or consequential liability element. They include:

- Insurance itself

- Any industry where maintenance contracts are sold

- All pure credit industries, eg bank loans, credit cards

- Any continuous supply which takes place under credit terms, eg utilities, industrial supplies

- Any situation in which claims are hard to validate

- Products where failure or misuse can cause significant damage to the consumers, leading to high incidence of product liability claims

Other areas of high risk include:

- Service industries where complainers - having taken service - often ask for reimbursement at full value

- Products or services where the costs the organisation has to incur to serve the consumer after the initial purchase may greatly outweigh the revenues if the consumer behaves in a certain way, eg cherry picks all the high cost, low or zero revenue parts of the service
- Situations where entitlement documentation can be forged

In order to give an idea of the extent and variety of 'bad consumer' situations, and their typical correlates, here are a few examples that differ from the usual example.

- Certain clothing shoppers (mostly women - because they are the majority of clothing shoppers) buy merchandise knowing that they are going to wear it once and take it back to the shop the next day to exploit the shop's liberal returns policy. Shops develop strategies to deal with this, typically taking the merchandise to the back office and smelling it for signs of body odour, deodorant, perfume etc - sure indicators of the garment having been worn for an extended period. If this is suspected, management is called in and the consumer is challenged.

- A very high percentage of claims on holiday insurance policies are fraudulent, particularly those involving claims of lost cash. Insurers are dealing with this by developing databases of frequent claimers and by using lie detectors.

- Certain passengers forge airline boarding passes to obtain frequent flyer points. One airline found that there was a correlation between forging and choosing ethnic meals.

- Certain utility users always pay at the very last minute, when they are about to be disconnected or have a prepayment meter fitted. One utility found this to be correlated with ethnic grouping.

- Certain consumers make a habit of claiming that different types of cleaning and washing fluids damage the item being cleaned - or, of course, their skin. They are traced by 
The collection of this licence was a very complex operation, made up from lots of different elements and carried out by a number of different parties. OgilvyOne was asked to try to increase the net licence fee income via a more integrated and targeted approach to marketing and communications planning. The starting point for segmentation was OgilvyOne's Evader Score Model, scoring every postcode in the country on propensity to be unlicensed. To this was added a wide range of lifestyle (including media), geodemographic and financial data to provide a rounded picture of different segments beyond simply their TV licence payment status. The most robust solution to emerge from cluster analysis involved seven segments. The data used to determine segments was a random sample of 50,000 postcodes, weighted by licensable addresses, enhanced by demographic and lifestyle data from several sources.

The fields used in segmentation were age, marital status, home ownership, length of residence, number and age of children, household size, income, newspaper readership. This allowed these questions to be answered:

- What is the most appropriate/productive way to contact them?

- How can we maximise/maintain the deterrent effect amongst them?

- What is the appropriate payment channel approach?

Direct marketing and web techniques were used to make evaders aware that their payment was sought and to make it easy for them to pay, resulting in a large rise in collection rates for the segments where research and data analysis had shown that customers were most likely to be responsive to efforts to make them pay.

Figure 1: Government consumer TV licensing case study

keeping properly computerised records of complainers' identities.

Companies can design products for bad consumers (tamper-proof electricity meters and phone booths, insurance products excluding specific risks, service products with prepayment tariffs). Slack product or service design, however, can turn good consumers into bad consumers - indeed whole markets from good to bad. For example, recruitment of consumers for cable telephony or motor insurance, irrespective of their propensity to pay their bills or to switch on price, led to many more consumers turning bad.

The government consumer TV licensing case study above (Figure 1) shows how licence evaders can be managed using consumer insight-based techniques.

\section{PREDICTION OF GOOD AND BAD CONSUMERS}

Risk and worth change over time, but companies are faced today with decisions which involve accepting consumers (or not) based on predicted value or risk. A good example of this is a typical student, who is currently high risk and low worth, yet courted expensively by all high street banks because of assumed future value. So, a critical factor that affects how 
organisations deal with good and bad consumers is their need to predict performance rather than observe it in retrospect. In particular, organisations are increasingly keen to use advanced information technology to check the status of an individual - not just during their relationship with him or her, but before the relationship is entered into - and predict any likely changes in value or status, especially from good to bad. This allows the organisation to price the relationship (eg in insurance or banking), change its terms (eg prepayment for utility bills), or to refuse to enter into it. Once the relationship begins, organisations find it harder to change prices or terms and typically accept the risk for the duration of the contract. If the consumer proves more risky than anticipated, the consumer may be trapped into receiving supply from the original organisation simply because knowledge of this higher level of risk means that no other organisation will offer the relationship. Here, the incidence may include an insurance claim, bad debt, crime, or even making several sales enquiries but never buying. The knowledge of past patterns of risk is vital for organisations trying to reduce risk, so they are keen to obtain and use this data as early as possible

- ideally before they open a dialogue with prospective consumers. Here, de-marketing can take the form of selecting apparently risky consumers out of marketing campaigns.

The above demonstrates a general point, that for a particular organisation to be able to define badness, let alone identify individual bad consumers, it must do one of two things:

1 Acquire data on apparent badness from other organisations.

2 Accept enough apparently bad consumers and observe/measure their behaviour, so that the organisation can learn to recognise them and avoid most of them in the future.

Note that as patterns of badness change, an organisation needs to refresh its knowledge. The organisation needs also to have enough good consumers (at least one at any time!) to enable it to define good too! Another general point is illustrated by the insurance example. To manage (and avoid or control) bad consumers, companies seek indicators not only of which consumers are likely to be bad already, but also which ones are turning from good to bad. For credit card companies, this may be a growing outstanding balance with no corresponding increase in monthly repayment. For a commercial consumer, this may mean extended periods of invoice settlement. Indicators may occur in other domains, however, to which a company has no access, eg payments to other companies - hence the importance of sharing data about creditworthiness or insurance risk.

\section{THE PORTFOLIO APPROACH}

In marketing, one of the principal issues at play is the balance between risk and consumer value. Companies can see their market as a consumer portfolio rather than as a set of product revenues. This leads to a focus on which kinds of consumer a company should aim to recruit or retain. The ideal is to develop a portfolio of consumers with value and risk balanced - either within or between consumers. The two may be associated; eg consumers with large houses may be more likely to be burgled, indeed, those with more wealth at risk may be tempted to make fraudulent declarations so as to obtain insurance cover at lower prices. 
Good consumers are not necessarily high value always. Good value is a net outcome over several years of buying behaviour. Some organisations develop predictive models not only to identify whether an individual who was not previously known to the organisation IS good or bad, but also to predict future states - in particular state changes. For example, a good individual turning bad exposes the organisation to risk.

'Knowing the consumer' is what small businesses have always done. The use of information on individual consumers has helped large organisations recover from the disadvantage of being large! They have been helped in doing this by companies dedicated to supplying this data and helping organisations to use it.

The larger a company becomes, and the more its commercial strategy pushes it in the direction of 'volume marketing', the more problematic the ideas of 'red lining' (avoiding completely certain categories of consumers) or 'cherry picking' (being very selective about which consumers to recruit) become. Many large companies cannot afford to cherry pick, as their business strategy is to focus on mass markets. They may not be able to 'red line' if their target consumers demand a simple, standard proposition.

\section{Controlling risk}

Together with statistical methods for focusing on good consumers and managing bad consumers come the usual strategies for controlling risk once bad consumers have been accepted. In insurance fraud, frequency and size of claim are both issues. There are well-established procedures for identifying likely sinners. Expansion of valid claims used to be harder to detect and/or manage, but many companies have specific strategies; eg appointing one's own repairers (as in the case of automotive crash damage). For areas such as fraudulent holiday claims, however, specialist loss adjusters use various formal and informal techniques to assess whether a claim is likely to be fraudulent and therefore whether to take the investigation further. A first step is always to see whether a given consumer keeps appearing on the 'bad' side of the consumer balance sheet. For example, frequent complainers about delayed rail journeys are identifiable once identities are checked and complaints properly logged. This has enabled companies to check whether the train that was claimed to be late actually was. Most markets define an acceptable level of moral hazard. Insurers have commonly accepted an estimated $10 \%$ fraudulent claim level, similar to the 'shrinkage' deemed acceptable in retail stocks (half of which is normally attributable to staff theft!). In some cases, however, this level exists because the company has not legitimised to its staff the idea that consumers may be hazardous but have instead confined it to one department (eg claims management, credit control, complaints management).

\section{Choosing consumers for positive - and negative - treatment}

Not every supplier can choose consumers. For example, public utilities and even retailers are usually under pressure to do business with any consumer, no matter how problematic or litigious. The issue is not just what consumers can do (in terms of giving or destroying value) if they want to, rather, it is a question of which consumers are most encouraged to buy and which not. By branding, marketing communications, store lay out, pricing, product range and all the other items of the marketing mix, particular kinds of consumer can be 
attracted while others can be deterred. For example, retail consumers requiring a close relationship may understand from the layout and staffing of a self-service store and the absence of any loyalty or store card scheme that they are unlikely to get their required relationship. In a department store, the layout and numbers of assistants and the existence of a combined store card and loyalty scheme give a different message.

\section{Making the decision about acceptable exposure and missed opportunity}

In theory, the more information about consumers a company has access to, the more accurately the company can assess consumers' current goodness or badness and the more accurately the company can predict future values. The decisions companies have to make range from the simple binary choice, eg whether to offer a specific product to a specific consumer, to more complex decisions eg which product to offer to which consumers, what terms to supply them under. There are diminishing returns to data, however, particularly as each data item collected has to be maintained (though of course there are diminishing returns to data maintenance as well). Where valuable consumers are rare, the returns to collecting the data that indicates likely future value can be high. To establish how much data needs to be collected and then maintained - companies need to estimate the link between the costs of data collection and maintenance and the benefits - not only overall but for each data item. 'Classic' direct marketing companies with long histories of consumer management can usually estimate the returns to using particular data items, but most companies simply do not have the stable data and analytical framework to achieve this.
A company's knowledge about the consumer becomes firmer after consumer acquisition, when a consumer's pattern of transactions, payments, complaints, queries etc becomes clear. Of course, the pattern is one thing, knowing the pattern is another - hence the deployment of advanced analytical techniques such as data mining.

\section{SOCIAL, POLITICAL AND LEGAL ISSUES}

The data usage practices of large organisations have attracted the attention of governments, social scientists, moral philosophers and others concerned with the ethics of organisational behaviour. The issues emerging in this area can be grouped broadly under the headings of:

- Organisational issues - how can the organisation achieve its objectives by using consumer data; and

- Public policy issues - what are the consequences of organisations doing this, and whether - and if so how - should governments constrain organisations' use of data?

Public issues take on particular significance in certain situations, in particular:

- Where the government has a direct influence on industry structure, whether as supplier or regulator (eg health care provision, public or private utilities, financial services); or

- Where there are significant ethical or social issues (eg the use of genetic data in life and medical insurance, the emergence of a category of uninsurable individuals or unbankable ethnic businesses which are 'red-lined' by suppliers).

In the USA, 'red lining' in insurance (eg 
in health) caused the government to identify 'pools' of uninsurables. Larger companies were forced to insure people from these pools at reasonable rates, taking a proportion of these customers related to their market share. This made it even more profitable for the niche 'cherry pickers' to operate against them, as it forced the larger companies to charge higher rates to cover the additional risk. This shows why heavy-handed government intervention can change industry behaviour to the disadvantage of 'good' consumers. In general, companies must use all available data, or else they will be subject to cherry picking of their 'good' consumers by competitors, leaving them just with 'bad' consumers. In addition, bad customers will seek out suppliers who cannot use data about their badness the problem of 'adverse selection'.

In the many situations in which individual consumer data is being used, there appears to be an emerging inconsistency of practice. For example, direct genetic data may not be used in the health and life insurance industry, whether for red-lining reasons or because some adverse medical conditions that are genetically correlated are also ethnically correlated, and ethnic bias is unacceptable. Indirect data, however, is acceptable, by asking about relatives' medical conditions. In other financial services sectors (eg motor insurance, banking for small businesses and consumers), it is common practice to note the ethnic bias in certain risks and use it to determine consumer recruitment policies and individual consumer pricing and risk management.

\section{ETHICAL ISSUES}

Conventionally, discrimination between individual consumers took two main forms:
- Creation of different offers according to affordability, so consumers could elect into different treatment according to their desire to spend money.

- Vetting - for credit-worthiness, fraud, previous claims etc and exclusion of certain consumers because of their predicted likely costs (whether legitimate or not!).

The sheer variety of the effects of the widespread use of data on good and bad consumers has caused those concerned with the societal effects of this data usage to think very hard about what is the right direction. One reaction has been to try to ban a variety of policies. The most obvious is the attempt to ban the use of data about an individual when the individual has not expressly consented to its use for the purpose in question. This idea underlies the drive towards a stronger data protection regime. This idea can either be considered very ethical or totalitarian! The truth is that governments use this data all the time for controlling 'bad consumers' - not necessarily criminals. For example, profiles of 'problem cases' are often developed and then applied to analyse a large number of cases to identify those likely to be problematic - a very different matter. This is the same approach that insurers apply - and would like to apply to identify whether a consumer has a genetic predisposition to certain illnesses. They - like governments - are simply interested in probabilities, as these are the key to reducing (not removing) risk.

This brings us to the banning of the use of data for probabilistic purposes the genetic issue is a good example. Capitalism lives on probabilities and risk, rarely on certainties. Owners of buildings thought to be more fireproof gathered together four hundred years ago to form 
mutual fire insurance organisations.

Excluding the use of probabilistic genetic data may lead to similar happenings. The central problem is that data collected for one purpose, eg to try to improve the health of an individual, or under one set of rules is often very useful for another eg insuring people fairly. This is a theme that recurs throughout marketing - eg the use of credit data used to include/exclude consumers from marketing campaigns or to predict crime.

Behind some attempts to restrict the use of consumer data is the view that those who hold the data cannot entirely be trusted to use it only for permitted purposes. Putting it simply, some are suspicious of the ethics of companies (eg are honest managers honest data users? Are retail staff more likely to abuse data?). Another source of criticism comes from those that know that 'bad' consumers (as defined by many companies) are biased towards certain ethnic or religious groups, social classes, geographical areas or even gender. As much political emphasis is placed on reducing bias, the use of data that would lead to the exclusion of certain consumer types from particular benefits is seen as back door discrimination, to be discouraged. A less radical view is that bias is built into society. Forcing companies not to use data to identify biases that affect them commercially will lead to other strategies that might be more insidious, such as red lining of geographical areas because they contain high proportions of risky consumers, even though use of consumer data and advanced risk assessment techniques would allow many consumers in the area to be served with low risk.

Unrestricted use of consumer data can lead to the emergence of categories of uninsurables and untradables. These consumers would not be able to receive a variety of products and services, would not receive certain communications (they would be subject to de-marketing) and might be confronted by outright refusal to supply, or be charged higher prices. Despite this, however, one can ask whether these problems are resolved just by legislation banning the use of certain data types. If risk is correlated with certain data items and use of these items is denied, smart capitalists will find good surrogates - as they do already.

\section{THE INTERNET, TRUST AND ALL THAT}

The internet has brought new focus to the issues surrounding the protection of data. Never before has there been such freedom of access to such immense amounts of personal information on a global scale. Countries such as the USA which value their open society and personal freedoms and find any bent towards totalitarianism deplorable are being forced to rethink how to deal with the balance between privacy and freedom of information. The success of a business depends upon the trust of its consumers. Individuals will not choose to do business with companies they do not trust. Trust cannot be won unless privacy is respected and security is assured. Respecting privacy and protecting personal data mean much more than mere adherence to laws and regulations. A company must put in place the standards and disciplines required to meet consumer expectations; it must practise the art of self-regulation. Those companies that harness their understanding of their consumers' data protection requirements will demonstrate integrity to their consumers. Their consumers will have confidence that their privacy is protected and their transactions are secure. Treating people the way they want to be treated can give companies a significant competitive edge. 
Opting in separately to all possible uses of consumer information would be virtually impossible. This makes it important to be a trustworthy business. No matter what a company promises, if it deceives consumers or uses information about them incompetently, it pays in the court of public opinion and eventually in revenue and profit.

\section{HOW DO CONSUMERS FEEL ABOUT THIS?}

Privacy is clearly an issue for some consumers, with physical privacy (the intrusion of direct marketing into their homes) representing an annoyance and information privacy (relating to the information available on consumers) representing a more substantial worry. In terms of the latter, respondents' level of knowledge varies substantially. People react in different ways. For example, some are pragmatic and recognise that the provision of personal details may improve targeting; however, those who feel particularly strongly attempt to minimise the information held on them and rarely, if ever, provide direct marketers with personal details or request communications from them. Interestingly, privacy concerns feature most strongly when respondents perceive that they are targeted with irrelevant marketing communications. The emotive response to this can vary from a general annoyance to overt concern, and the strongest reaction is to actively withdraw from direct marketing communications. Direct mailers do not like the term 'junk mail'. It applies to mail that is perceived by the recipient as being uninteresting or irrelevant.

\section{WHAT DOES THE LAW SAY?}

The kind of questions consumers might ask about the use of their data relate to:
- Who has what data about them?

- What use they are making of that data:

- Is the data correct?

- How the use of the data is likely to affect them?

- Whether data from different databases have been merged?

- Who did that merging and why?

- Whether they will they be told about the use to which data which relates to them has been put, even if they are not affected directly?

- Whether others will get rich from the sale, resale and acquisition of data about them?

- Whether they will get a royalty or some other reward for data they give, and if not why not?

Privacy and data protection legislation and practice, or industry codes of practice, aim to provide answers to some of these questions, or to make it unnecessary to ask some of them. Many industries have their own codes of practice (eg banking). These aim to ensure that companies follow good practice, pre-empting government intervention and ensuring that consumers are not dissatisfied because of how they are treated. The problem with self-regulation is that it relies on goodwill. The risk is that companies observe the regulations superficially, but disregard them in practice. Self-regulation that fails may be worse than waiting for the government to act, because consumers have, in the interim, been lulled into a false sense of security.

This is not the place to cover the specific laws and regulations as they vary from country to country, change over time, relate both to data and to the media used to contact consumers (including e-mail and mobile messaging) and are susceptible to varied and changing interpretation. Readers are 
referred to the government data protection of privacy bodies and their websites, to the code of practice of the market research association in their country and, of course, to their own legal advisers.

\section{IMPROVING THE QUALITY OF CONSUMER DATA MANAGEMENT SO AS TO COMPLY}

While the many legal and administrative issues surrounding data protection directives are unclear, the requirements it places on consumer information management are known. Companies need to:

- Provide accurate, complete and consistent client information to their business systems. Without this, compliance to data protection directives will prove difficult and costly to provide.

- Provide accurate information on relationships. For example, key relationships such as legal guardian, spouse, parent are important as they determine who is entitled to access personal information.

- Provide complete and accurate information on what services and products a client has purchased. For example, a client's credit may be withheld due to an inaccurate account balance.

- Ensure that operational business systems have a common enterprise view of the client and that any updates to client information are reflected across the whole enterprise.

- Ensure that rules relating to creating new consumer information are applied consistently. This may include enforcing the capture of certain mandatory information such as privacy and non-solicitation status.

- Ensure that new consumer data is captured, accessed and updated consistently and used properly.

- Understand what personal information is captured and why it is captured, who can create, update and delete it.

- Be able to demonstrate compliance with data protection directives to the relevant statutory bodies.

\section{GUIDELINES FOR DATA PROTECTION}

Here are some guidelines to follow. They may or may not be legally required in some countries, but the present authors would argue that they constitute good practice.

- Treat manual records like computer records, particularly concerning consumer access.

- Check all manual records for compliance.

- Check all forms on which personal data is obtained to ensure that they contain the necessary consent notices, particularly in relation to any sensitive data. At source, the data must be collected fairly. Make it clear to the consumer what it is going to be used for.

- Use data according to the business purpose for which it has been collected, which should also be the one explained clearly to consumers at or before the time of collection.

- Clarify to consumers how you intend to use data within your organisation (eg for cross-selling).

- Ensure your legal advisors are closely involved in reviewing existing practice and in any changes in practice. Ensure they understand your business purposes and can therefore advise you as to what you can do, not just what you can't do!

- Extend existing systems for giving access to computerised data to 
word-processed and manual data. Where the data is really essential, it may be better to computerise it to ease access (eg through text search engines) and higher quality processing.

- Ensure all processing of personal data is only on one of the allowed grounds, including those for sensitive data. The data must always be processed fairly. For example, is it fair for an individual to be grouped with neighbours (or indeed any other individuals) for the purposes of credit assessment?

- Do not continue old practices without thinking. Ask whether old processes comply with current law. If not, can the same objective be achieved in a different way?

- Check that procedures meet all requirements for informing consumers when obtaining or disclosing data.

- Ensure consumer access procedures conform to access requirements. Ensure they can service high volumes of requests.

- Any automated systems that use personal data should be especially carefully checked for compliance in particular can the reasoning behind the processing be explained 'manually'?

- Network and website infrastructure should be checked to ensure that any personal data given to or posted on them is processed according to the Data Protection Act.

- Check that any data you allow to be viewed by a third party, or that you transfer to a third party, receives adequate protection. Check for contractual safeguards.

- Keep up to date with advice and practice.

- Always provide opt-out boxes to allow consumers to refuse to let their data be used for additional purposes. If you want to be really certain of where you stand, use opt-in boxes.

\section{CONCLUSIONS}

Consumers have a right to expect companies to manage their data professionally. This is not just a marketing question - financial issues are at stake too. Companies should review how far their own practices match best practice and establish strategies and targets to improve their practice. In a world where identification and management of good consumers brings rich rewards, try to follow these guidelines.

1 Define good and bad consumers, recognising that most consumers have a mix of good and bad attributes.

2 Remember, bad consumers often occur in groups, may work together, may collude with your staff and get better at being bad if you let them ie they learn. So do not assume the situation is static.

3 Don't be afraid to 'think the unthinkable', in terms of how 'badness' may be distributed, but make sure that you base your analyses on hard evidence, not prejudice, and that you stay clearly within the terms of the various laws that determine what you can do. These include laws covering data protection, racial and other types of discrimination, employment and specific industry regulations.

4 Ensure that your databases and data sources allow you to identify good and bad consumers.

5 If you can, measure the performance of your business in terms of the net value you obtain from each consumer — including all exposures and not just routine costs. Where you do not have individual consumer revenues and 
costs, use research-based estimates.

6 Estimate your net exposure to bad consumers and calculate if it is worth investing in reducing exposure.

7 If it is worthwhile, make sure that your systems at the point of contact with consumers allow you to identify bad consumers and to predict whether a new consumer will be good or bad.

8 Where the data you need to do this is somewhere else, obtain it and, if possible, develop relationships with your competitors which allow you to identify bad consumers and warn each other about them - subject to the provisions of the Data Protection Act and any special industry regulation.

9 Develop, test and refine different strategies to deal with bad consumers, combining limits to or refusal to dealing with techniques to reduce exposure to bad consumers who have 'got through'.

(C) Bryan Foss \& Alison Bond

\section{Acknowledgments}

This paper was originally published as Chapter 10 in 'Consumer Insight: How to Use Data and Market Research to Get Closer to Your Customer' by Bryan Foss, Alison Bond and Merlin Stone. ISBN: 0749442921. It is reproduced by kind permission of Kogan Page, London.

Special offer for subscribers to the Journal of Database Marketing \& Customer Strategy Management - order your copy of Consumer Insight (ISBN 07949442921) at $20 \%$ discount. Visit www.kogan-page. co.uk and enter code HSC105 to obtain your discount. 